11 Сорокопудов В.Н., Мелькумова Е.А. Биологические особенности смородины и крыжовника при интродукции: монография. РАСХН. Сиб. Отделение. - Новосибирск, 2003. - 296 с. - ISBN: 5-94306-111-8.

12. Keller J. Zur Rolle in vitro-Kultur in Genbanken // Vortr. Pflanzenzucht. - 1994. - № 27. - S. 287-295.

\title{
PRESERVING SANITIZED PLANTS OF BLACK CURRANT IN ORDER TO CREATE GENETIC BANKS
}

\author{
Sorokopudov V. N., Knyazeva I. V. \\ Federal State Budgetary Scientific Institution \\ "Russian Selection and Technological Institute of Horticulture and Nursery Breeding", \\ c. Moscow, Russia,e-mail: sorokopud2301@mail.ru
}

The paper presents the results on the development and preservation of black currant promising cultivars from the genetic collection of the given institution, using cultivar samples that are bred by the leading Russian scientific institutions. There was started a research on creating and maintaining Ríbes L. collection in vitro; at the moment, depositing technology is being practiced. Currently, our collection fund has 31 black currant cultivars, 10 of which are introduced into in vitro. The creation of in vitro bank not only helps to develop the research on preserving plant biodiversity, but also is the basis for studying fundamental problems in plants physiology and biochemistry, including genetic and breeding works.

Key words: black currant, cultivar, in vitro collection, genetic resources, preserving biodiversity.

УДК 635.932:631.52(471.63)

\section{ИНТРОДУКЦИЯ СОРТОВ ТУИ (ТНUJA L.) НА ЮГЕ РОССИИ}

\author{
Хупов Р. Б. \\ ООО «Прекрасныле сады»», \\ 2. Краснодар, Россия, e-mail: beautiful-garden@inbox.ru
}

\begin{abstract}
Представлены итоги комплексной оценки новых интродуцированных сортов туи (Thuja L.) 'Brabant', 'Degroots Spire', 'Malonyana', 'Mini Smaragd', 'Atrovirens', 'Can-Can' и 'Dura' в условиях Краснодарского края по основным адаптивным признакам и декоративным свойствам. Установлено, что декоративные показатели сортов туи определяются сортовой спецификой, прежде всего относительной устойчивостью к болезням и абиотическим стресс-факторам в конкретных условиях произрастания. Выделены наиболее адаптивные в сочетании с высокими декоративными показателями (архитектоника кроны, цвет и аромат хвои, период декоративности и др.) сорта туи 'Degroots Spire', 'Mini Smaragd', 'Atrovirens' и 'Dura', рекомендуемые для
\end{abstract}


Глава 2. Интродукция и сортоизучение

расширения регионального сортимента туи (Thuja L.) и широкого использования в озеленении на юге России.

Ключевые слова: туя, вид, сорт, адаптивность, декоративность, устойчивость, озеленение, садовый ландшафт.

В ландшафтном строительстве важная роль отводится хвойным растениям, которые, являясь вечнозелёными, сохраняют декоративность в течение года, что увеличивает их ценность и востребованность $[1,8,12]$.

Видовой состав хвойных растений широкий и разнообразный. Особое место среди хвойных растений занимает род (Thuja L.), подсемейство Туевые (Thujoideae), семейство Кипарисовые (Cupressaceae) [3, 5].

B настоящее время сортимент туи (Thuja L.) объединяет свыше 120 сортоформ, которые ценятся за содержание эфирных масел, активное выделение фитонцидов, высокую степень устойчивости к загрязнению воздуха $[1,12]$.

В России основными представителями рода Thuja L. являются туя западная (Thuja occidentalis L.) и туя пликата (Thuja plicata L.). Coвременный сортимент туи представлен большим количеством новых интродуцированных сортов, большинство которых не оценены в условиях возделывания, что вызывает необходимость их комплексной оценки в условиях южного региона $[5,2]$.

Методы и объекты исследования. Объектом исследований были представители двух видов туи: 4 сорта 'Brabant', 'Degroots Spire', 'Malonyana', 'Mini Smaragd', относящиеся к виду туя западная (Thuja occidentalis) и 3 сорта 'Atrovirens', 'Can-Can' и 'Dura', относящиеся к виду туя пликата (Thuja plicata). Контроль - сорт туи западной 'Smaragd' - самый распространённый, широко используемый в садовом ландшафте, как в южном регионе, так и на территории РФ.

Комплексная оценка сортов туи проводилась в 2014-2017 гг. по методикам государственного сортоиспытания растений (1968) [9]; на основе методических указаний Ярославцева Г. Д., Булыгина Н. Е., Кузнецова С. И. (1973) [13]; при оценке декоративных качеств использованы методические подходы Котеловой Н. В. (1974) [6]; Рязановой Н. А., Путенихина В. П. (2011) [10]; Былова В. Н. (1978) [3]; Захаренко Г. С. (2006) [4]; Крековой Я. А., Даничевой А. В., Залесова С. В. (2015) [7], а также по усовершенствованным методикам Савушкиной, С. С. СеитАблаевой (2015 г.) [11].

Результаты и обсуждение. На фоне комплекса стресс-факторов, имевших место в годы исследований, была дана оценка зимостойкости, засухоустойчивости интродуцируемых сортов туи. 
Высокой зимостойкостью характеризовался сорт туи 'Atrovirens', у которого все годы практически отсутствовали зимние повреждения. Устойчивость на уровне контроля (4 балла) к зимним повреждениям была у сортов 'Brabant', 'Malonyana' и 'Dura', у которых проявлялись незначительные изменения окраски хвои и отдельные пожелтевшие побеги, количество отмерших побегов не превышало $10 \%$. Более низкая зимостойкость проявилась у сортов 'Degroots Spire', 'Mini Smaragd' и 'Can-Can', у которых количество отмерших побегов превышало 30-40 \% поверхности всего растения (табл. 1).

При подсчёте общего балла адаптивности сортов туи к биотическим и абиотическим стрессам был введён переводной коэффициент значимости $(\mathrm{P})$. По признакам зимостойкость, засухоустойчивость и устойчивость к болезням коэффициент Р был приравнен к 2, по ветроустойчивости к 1 (табл. 1).

Высокая засухоустойчивость (5 баллов) отмечалась у сортов 'Mini Smaragd' и 'Degroots Spire', проявлявшаяся хорошим общим состоянием, т. е. когда цвет хвои не изменялся и продолжался рост растений (табл. 1).

Ветроустойчивость - один из важных показателей в оценочной шкале. В изученной группе сортов признак ветроустойчивость сильно не варьировал. Так, у сортов 'Brabant', 'Malonyana' и 'Atrovirens' он соответствовал 4 баллам, у сортов 'Degroots Spire', 'Mini Smaragd', 'Can-Can' и 'Dura' - 5 баллам. Все изучаемые сорта туи отнесены к ветроустойчивым (табл. 1).

Характеристика разных сортов

Таблиияа 1

\section{Thuja occidentalis и Thuja plicata по основным адаптивным признакам, 2014-2017 гг.}

\begin{tabular}{|l|c|c|c|c|c|}
\hline \multirow{2}{*}{ Сорт } & $\begin{array}{c}\text { Зимо- } \\
\text { стойкость, } \\
\text { балл }\end{array}$ & $\begin{array}{c}\text { Засухо- } \\
\text { устойчи- } \\
\text { вость, } \\
\text { балл }\end{array}$ & $\begin{array}{c}\text { Пораже- } \\
\text { ние боле- } \\
\text { нями, } \\
\text { балл }\end{array}$ & $\begin{array}{c}\text { Ветро- } \\
\text { устой- } \\
\text { чивость, } \\
\text { балл }\end{array}$ & $\begin{array}{c}\text { Общий } \\
\text { балл, } \\
\text { (мах= 35) }\end{array}$ \\
\cline { 2 - 5 } & $\mathrm{P}=2$ & $\mathrm{P}=2$ & $\mathrm{P}=2$ & $\mathrm{P}=1$ & 28 \\
\hline 'Smaragd' (к) & $4 / 8$ & $4 / 8$ & $4 / 8$ & $4 / 4$ & 28 \\
\hline 'Brabant' & $4 / 8$ & $4 / 8$ & $4 / 8$ & $4 / 4$ & 31 \\
\hline 'Degroots Spire' & $3 / 6$ & $\mathbf{5 / 1 0}$ & $5 / 10$ & $5 / 5$ & 30 \\
\hline 'Malonyana' & $4 / 8$ & $4 / 8$ & $5 / 10$ & $4 / 4$ & 29 \\
\hline 'Mini Smaragd' & $3 / 6$ & $\mathbf{5 / 1 0}$ & $4 / 8$ & $5 / 5$ & 28 \\
\hline 'Atrovirens' & $4 / 8$ & $4 / 8$ & $4 / 8$ & $4 / 4$ & 25 \\
\hline 'Can-Can' & $3 / 6$ & $4 / 8$ & $3 / 6$ & $5 / 5$ & 29 \\
\hline 'Dura' & $4 / 8$ & $4 / 8$ & $4 / 8$ & $5 / 5$ & \\
\hline
\end{tabular}


Глава 2. Интродукция и сортоизучение

Туя считается устойчивой к болезням и вредителям $[1,2]$. Однако необходимо отметить, что часто корневая система растений поражается фитофторой, вызывающей гибель корневой системы, а также настоящим шютте и обыкновенным шютте, возбудитель которых вызывает характерное пожелтение и преждевременное опадение хвои.

В период проведения исследований чаще всего отмечались поражения растений обыкновенным шютте (Lophodermium pinastri Chev.). Оценка устойчивости, проведённая по 5-балльной системе, показала, что поражение растений варьировало от 3 до 5 баллов. Высокая устойчивость к шютте на уровне 5 баллов отмечалась у сортов 'Malonyana' и 'Degroots Spire'. Устойчивость на уровне 4 баллов отмечена у сортов 'Brabant', 'Mini Smaragd', 'Atrovirens' и 'Dura'. Сравнительно ниже она была у сорта 'Can-Can' и соответствовала 3 баллам (табл. 1).

В целом изученные сорта туи были устойчивы к вредителям. В 2014-2015 гг. отмечались незначительные повреждения в пределах 4 баллов туевой минирующей молью (Aphidoidea Latreille) и щитовкой (Carulaspis caruelii), проявлявшиеся в усыхании отдельных ветвей, пожелтение и опадении хвои. В 2017 г. отмечалось незначительное повреждение лубоедом кипарисовым (Phloeosinus armatus).

Таким образом, сравнительная оценка сортов туи по комплексу признаков устойчивости к абиотическим и биотическим факторам позволила сделать вывод, что все изученные сорта являются адаптивными. К сортам с комплексной устойчивостью были отнесены сорта 'Brabant', 'Malonyana', 'Atrovirens' и 'Dura'. Сорта 'Degroots Spire', 'Mini Smaragd' при общих высоких баллах характеризовались пониженной зимостойкостью. Сорт 'Can-Can' выделился более слабой зимостойкостью и устойчивостью к болезням.

Декоративные качества сортов туи оценивались по следующим признакам и показателям: архитектоника кроны; окраска кроны в летний и зимний период; аромат хвои. Помимо декоративных признаков, отмечался период максимальной декоративности. Каждый признак оценивали по 5-балльной шкале. При расчёте общего балла каждый полученный балл индексировали за счёт переводного коэффициента значимости (Р), величина которого определялась продолжительностью действия каждого признака и силой его эстетического воздействия (табл. 2).

По комплексу признаков, определяющих архитектонику кроны, сорта туи 'Mini Smaragd', 'Degroots Spire' и 'Malonyana' были на уровне контроля. Сорта 'Brabant', 'Atrovirens', 'Can-Can' и 'Dura' по этому показателю немного уступали контролю и были оценены в 4 балла (табл. 2). 
Характеристика сортов Thuja occidentalis и Thuja plicata по основным декоративным признакам, 2014-2017 гг.

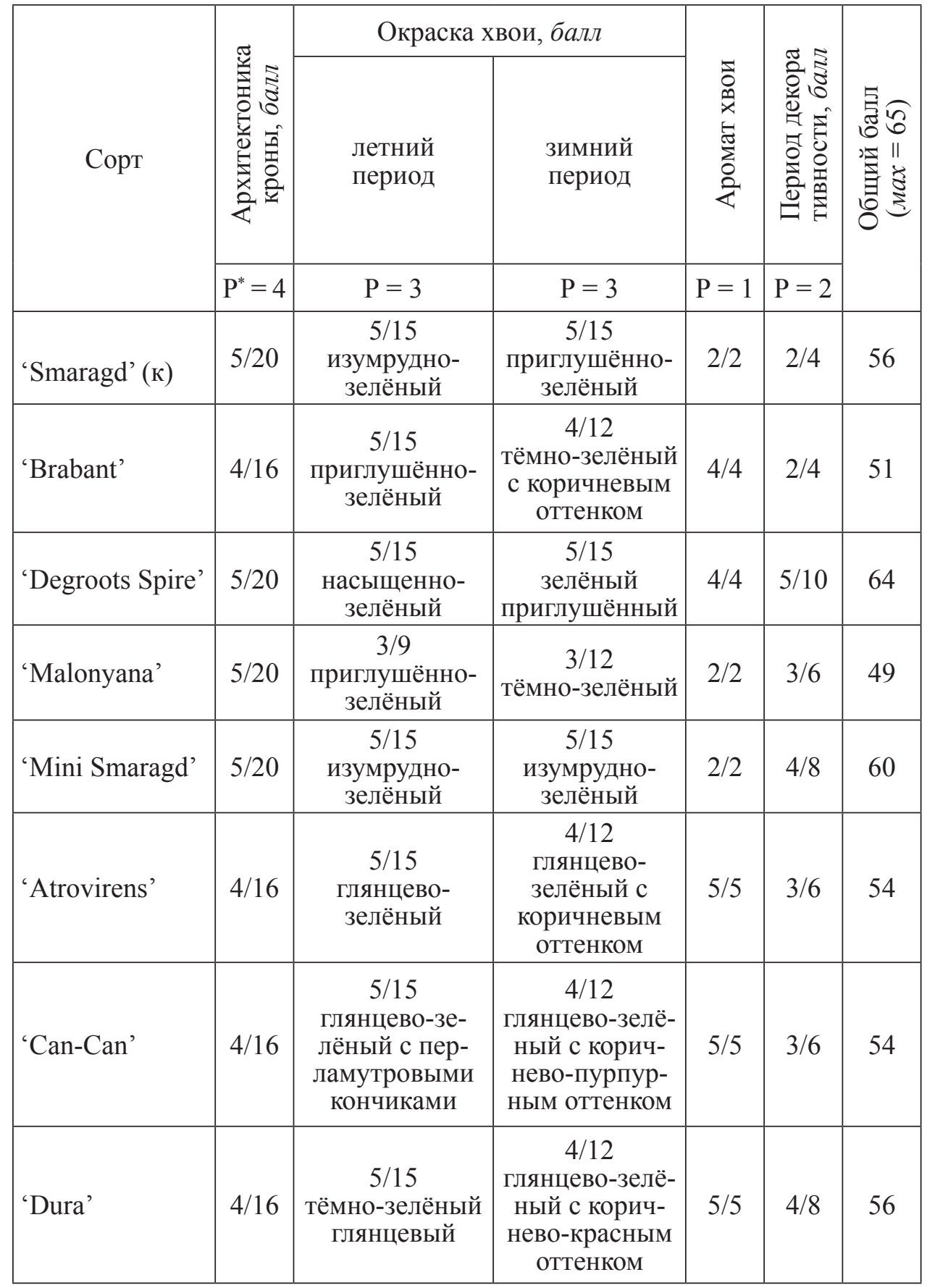

Примечание: $\mathrm{P}^{*}$ - коэффициент значимости признака декоративности 
Глава 2. Интродукция и сортоизучение

Проведённые наблюдения за сортами в зимний и летний период позволили определить особенности в изменении цвета хвои. Так, летом основная часть сортов 'Dura', 'Can-Can', 'Atrovirens', 'Mini Smaragd', 'Degroots Spire' имела тёмно-зелёный с глянцевым отливом цвет хвои, сорт 'Brabant' - приглушённо-зелёный (табл. 2).

К середине зимы цвет хвои у всех сортов туи изменялся. Многие сорта приобретали коричневатый, пурпурово-красный оттенок хвои, что снизило оценку у некоторых сортов до 3 баллов и повлияло на оценку периода декоративности. При этом необходимо отметить, что, по мнению современных специалистов и дизайнеров по ландшафтному дизайну, изменение окраски хвои у некоторых сортов туи не является недостатком, а скорее преимуществом как признак, отражающий сезонность изменения.

В 4-5 баллов оценены сорта 'Dura', 'Mini Smaragd' и 'Degroots Spire’, чья окраска хвои практически не изменялась в сравнении с летней окраской. Более низкую оценку получили сорта, у которых в зимний период декоративный эффект снижался, - 'Can-Can', 'Atrovirens', 'Brabant' и 'Malonyana'.

По аромату хвои сорта туи были распределены на две группы: сорта со специфичным ароматом хвои - 'Brabant', 'Degroots Spire', 'Mini Smaragd'; сорта с приятным интенсивным смолистым ароматом хвои 'Atrovirens', 'Can-Can' и 'Dura' (табл. 2).

Согласно полученным данным, сорта туи по декоративным признакам были распределены на 2 группы. В первую были включены сорта 'Dura', 'Mini Smaragd' и 'Degroots Spire' с высоким общим баллом 56-64. Во вторую - сорта с более низким общим баллом 49-54: 'Malonyana', 'Brabant', 'Atrovirens' и 'Can-Can' (табл. 2).

Комплексная оценка новых сортов - интродуцентов туи - по адаптивности и комплексу декоративных признаков позволила выделить лучшие сорта: 'Degroots Spire', 'Mini Smaragd', 'Dura' и 'Atrovirens', - общая оценка которых была высокой и варьировала в пределах 82-95 баллов. Сорта туи 'Can-Can', 'Malonyana' и 'Brabant', по общей оценке, были несущественно ниже контроля, что даёт основание говорить об их перспективности (табл. 3).

Выводы. По результатам оценки новых интродуцированных сортов туи в условиях южного региона по комплексу признаков устойчивости к температурным стрессам и болезням, выделены сорта 'Degroots Spire', 'Malonyana', 'Dura' и 'Mini Smaragd'; по комплексу ценных декоративных признаков: архитектоника кроны, окраска хвои, аромат хвои, период декоративности - 'Degroots Spire', 'Mini Smaragd', 'Dura'; по комплексу устойчивости к стресс-факторам и декоративных признаков - 'Degroots 
Spire', 'Mini Smaragd', 'Dura', рекомендуемые для широкого использования в различных садовых ландшафтах на юге России.

Таблица 3

Комплексная оценка

новых интродуцированных сортов туи

в условиях Краснодарского края, 2014-2017 гг.

\begin{tabular}{|l|c|c|c|}
\hline \multicolumn{1}{|c|}{ Сорт } & $\begin{array}{c}\text { Общий балл } \\
\text { по признакам } \\
\text { устойчивости } \\
\text { (мах =35) }\end{array}$ & $\begin{array}{c}\text { Общий балл } \\
\text { по декоративным } \\
\text { признакам } \\
\text { (мах }=65)\end{array}$ & $\begin{array}{c}\text { Общий балл } \\
\text { по комплексу } \\
\text { признаков } \\
\text { (мах=100) }\end{array}$ \\
\hline 'Smaragd' (к) & 28 & 56 & 84 \\
\hline 'Brabant' & 28 & 51 & 79 \\
\hline 'Degroots Spire' & 31 & 64 & 95 \\
\hline 'Malonyana' & 30 & 49 & 79 \\
\hline 'Mini Smaragd' & 29 & 60 & 89 \\
\hline 'Atrovirens' & 28 & 54 & 79 \\
\hline 'Can-Can' & 25 & 54 & 85 \\
\hline 'Dura' & 29 & 56 & \\
\hline HCP & & & \\
\hline
\end{tabular}

\section{Библиографический список}

1. Александрова М.С., Александров П.В. Хвойные растения в вашем саду. - Ростов н/Д: Феникс, 2005. - С. 42-56. - ISBN: 5-222-06441-7.

2. Аннотированный каталог растений Ботанического сада Крымского федерального университета им. В. И. Вернадского / под ред. А.И. Репецкой. - Симферополь: Ариал, 2014. - 184 c. - ISBN: 978-617-648-308-3.

3. Былов В.Н. Основы сравнительной сортооценки декоративных растений // Интродукция и селекция цветочно-декоративных растений. - М.: Наука, 1978. - С. 7-31.

4. Захаренко Г.С. Биологические основы интродукции и культуры видов рода кипарис (Cupressus L.). - Киев: Аграрна наука, 2006. - С. 126-159. - ISBN: 966-540-071-1.

5. Карпун Ю.Н., Перфильева Г.Ф. Классификация садовых форм туи западной (Thuja occidentalis L.) // Hortus botanicus. - 2004. - № 2. - C. 33-41. - eISSN: 1994-3849.

6. Котелова Н.В., Виноградова Н.В. Оценка декоративности деревьев и кустарников по сезонам года // Физиология и селекция растений, озеленение городов. - М.: МЛТИ, 1974. - С. 37-44.

7. Крекова Я.А., Даничева А.В., Залесов С.В. Оценка декоративных признаков у видов рода Picea Dieter в Северном Казахстане // Современные проблемы науки и образования. - 2015. - № 1. - С. 16-23. - eISSN: 2070-7428. [Электронный ресурс]. - URL: www.science-education.ru/121-17204.

8. Мартынова Н.А. Эколого-биологические особенности древесных растений при интродукции в Белгородской области: автореф. дис. ... к.б.н. - Саратов, 2009. - С. 10-13. 
9. Методика государственного сортоиспытания сельскохозяйственных культур. Вып. 6 (декоративные культуры). - М.: Колос, 1968. - С. 112-146.

10. Рязанова Н.А., Путенихин В.П. Оценка декоративности клёнов в Уфимском Ботаническом саду // Вестник ИрГСХА. - 2011. - Т. 4. - № 44 С. - 121-128. ISSN: 1999-3765.

11. Савушкина И.Г., Сейт-Аблаева С.С. Методика оценки декоративности представителей рода Juniperus L. // Экосистемы. - 2015. - № 1(31). - C. 97-105. - ISSN: 2414-4738. 12. Шевырёва Н., Коновалова Т. Хвойные растения. Большая энциклопедия. - М.: Эксмо, 2012. - С. 78-82. - ISBN: 978-5-699-51415-1.

13. Ярославцев Г.Д., Булыгин Н.Е., Кузнецов С.И., Захаренко Г.С. Фенологические наблюдения над хвойными: метод. указ. - Ялта, 1973. - С. 26-32.

\title{
INTRODUCING ARBORVITAE CULTIVARS (THUJA L.) IN THE SOUTH OF RUSSIA
}

\author{
Khupov R. B. \\ LLC "Beautiful Gardens", \\ c. Krasnodar, Russia, e-mail: beautiful-garden@inbox.ru
}

The paper presents a comprehensive assessment of the new following arborvitae (Thuja L.) cultivars: 'Brabant', 'Degroots Spire', 'Malonyana', 'Mini Smaragd', 'Atrovirens', 'Can-Can' and 'Dura', introduced in Krasnodar region by the main adaptive features and ornamental properties. It was found out that arborvitae ornamental indices in each cultivar are determined by varietal specificity, especially by relative resistance to diseases and abiotic stress factors under specific growth conditions. The most adaptive arborvitae cultivars: 'Degroots Spire', 'Mini Smaragd', 'Atrovirens' and 'Dura', combining high ornamental indices (architectonics of the crown, color and aroma of the needles, ornamental period, etc.) were identified as being highly adaptive and ornamental; they are recommended to expand the regional arborvitae assortment and to be widely used in gardening in the South of Russia.

Key words: arborvitae, species, cultivar, adaptability, ornamental qualities, resistance, gardening, garden landscape. 